\title{
Cognitive and Serotonergic Vulnerability to Depression: Convergent Findings
}

\author{
Linda Booij and A. J. Willem Van der Does \\ Leiden University
}

\begin{abstract}
Cognitive reactivity $(\mathrm{CR})$ is a psychological vulnerability marker of depression, whereas response to acute tryptophan depletion (ATD; a serotonergic challenge procedure) is a biological vulnerability marker. The aim of this study was to investigate the relationship between these markers. Thirty-nine remitted depressed patients participated in 2 ATD sessions in a double-blind crossover design. CR, assessed prior to the ATD sessions, predicted depressive response to high-dose ATD. CR also diminished the effects of 2 known predictors of ATD response: gender and residual symptoms. Neuroticism and behavioral inhibition were unrelated to ATD response. CR is associated with an increased sensitivity to reductions of serotonin concentrations. These findings present a small step toward unifying cognitive and neurobiological theories of depression.
\end{abstract}

Keywords: depression vulnerability, remitted depressed patients, cognitive reactivity, acute tryptophan depletion, serotonin

Although depressive episodes can be treated with antidepressant medication, structured forms of psychotherapy, or both (DeRubeis et al., 2005; Keller, 1999), the rate of recurrence is high (Judd, Paulus, \& Zeller, 1999; Mueller et al., 1999). Identifying individuals at high risk of relapse might improve overall outcome. There are a number of promising vulnerability markers of depression. Biological markers include response to pharmacological challenges such as the dexamethasone/corticotropin releasing hormone (DEX-CRH) test (Ising et al., 2005) and response to acute tryptophan depletion (Moreno, Henninger, McGahuey, \& Delgado, 2000). Promising psychological vulnerability markers include cognitive reactivity (Segal, Gemar, \& Williams, 1999), rumination (Kuehner \& Weber, 1999), and information-processing indices (Elliott, 1998).

The impact of biological manipulations on information processing has been investigated in recent studies. Acute tryptophan depletion, a method that temporarily lowers serotonin (5hydroxytryptamine; 5-HT) function (Young, Smith, Pihl, \& Ervin, 1985), impaired memory consolidation (Riedel, Klaassen, Deutz,

Linda Booij, Department of Psychology, Leiden University, Leiden, the Netherlands; A. J. Willem Van der Does, Department of Psychology, Leiden University, and Department of Psychiatry, Leiden University Medical Center.

Linda Booij is now at the Department of Psychiatry, McGill University, Montreal, Quebec, Canada.

This work was supported by grants from the Netherlands Organization of Sciences-Medical Sciences (NWO-MW Grant 904-57-132) and the Foundation Stichting tot Steun VGGCZ. Part of the data has been presented at the Congress of the Collegium Internationale Neuro-Psychopharmacologicum, Paris, France, in June 2004. We thank Kevin F. Casey for helpful comments.

Correspondence concerning this article should be addressed to A. J. W. Van der Does, Department of Psychology, Leiden University, Wassenaarseweg 52, 2333 AK Leiden, the Netherlands. E-mail: vanderdoes@fsw.leidenuniv.nl van Someren, \& Van Praag, 1999; Schmitt et al., 2000) and emotional processing in both healthy volunteers (Harmer, Rogers, Tunbridge, Cowen, \& Goodwin, 2003; Murphy, Smith, Cowen, Robbins, \& Sahakian, 2002; Young et al., 1985) and remitted depressed patients (Booij, Van der Does, Haffmans, Riedel, et al. 2005). Improving 5-HT function with the selective serotonin reuptake inhibitor (SSRI) citalopram $(20 \mathrm{mg} /$ day) over 7 days facilitated the recall of positive information but impaired the detection of facial expressions of anger and fear in healthy volunteers (Harmer, Mackay, Reid, Cowen, \& Goodwin, 2006; Harmer, Shelley, Cowen, \& Goodwin, 2004). These findings suggest that both cognitive and symptomatic changes are part of the same overall response to 5-HT manipulation and that cognitive changes occur at a lower threshold, or that they may be two independent effects. Administration of the 5- $\mathrm{HT}_{2}$ agonist fenfluramine in healthy volunteers improved dysfunctional attitudes without significantly affecting mood (Meyer et al., 2003), suggesting that changes in 5-HT may activate or deactivate depression-related schemas. Both serotonergic and noradrenergic systems are implicated in the pathophysiology of depression, and they are the most promising targets for treatment (Maes \& Meltzer, 1995; Morilak \& Frazer, 2004). Manipulations of these neurotransmitter systems, with medication or experimental challenge procedures, have characteristic effects on cognition (Booij, Van der Does, \& Riedel, 2003); however, most research has focused on the 5-HT system.

The present study was designed to investigate the relationship between a serotonergic and a cognitive marker of depression vulnerability. Although the cognitive effects of biological manipulations have been the subject of some recent research, the relationship of cognitive vulnerability and biological vulnerability has not been investigated. In the present study, we focused on a serotonergic challenge procedure called acute tryptophan depletion (ATD). This procedure temporarily lowers 5-HT function by depleting its precursor L-tryptophan (Trp). ATD is induced by a 1-day, low-Trp diet, followed by the ingestion of a mixture of all 
essential amino acids (AAs) except Trp (Young et al., 1985). ATD reduces plasma Trp levels by $75 \%-90 \%$ in $5-7 \mathrm{hr}$, and central 5-HT function is also impaired (Carpenter et al., 1998; Nishizawa et al., 1997).

It has often been demonstrated that a high-dose ATD (75-102.5 g AAs) transiently exacerbates symptoms in about $50 \%$ of patients in remission from depression (Van der Does, 2001). The symptoms elicited by ATD are specific to depression (Booij, Van der Does, Haffmans, Spinhoven, \& McNally, 2005), and the effects are largest in patients treated with SSRIs (Delgado et al., 1999). ATD is a challenge procedure, but patients do not regard the procedure as problematic (Booij, Van der Does, Haffmans, Spinhoven, \& McNally, 2005). Furthermore, more than 220 ATD studies have been published since 1977. These studies involved more than 3,900 participants, many with a psychiatric disorder, and no adverse events have been reported. Early research findings presented ATD as a tool to investigate the mechanism of action of antidepressant treatment (Delgado et al., 1990), but more recent research indicates that ATD response not only is related to prior treatment modality but also reflects individual vulnerability to depressive relapse. For instance, unmedicated recovered depressed patients also respond to ATD (Neumeister et al., 2004; Smith, Fairburn, \& Cowen, 1997). Furthermore, gender, chronicity of depression, and history of suicidal ideation are independent predictors of depressive response to ATD (Booij et al., 2002). In most studies, ATD causes no significant changes in mood in healthy samples. If mood does change significantly in never-depressed samples, the effect is rather small and is limited to depressionvulnerable individuals, for example, first-degree relatives of patients with depression (Benkelfat, Ellenbogen, Dean, Palmour, \& Young, 1994; Klaassen et al., 1999). Finally, preliminary findings indicate that the response to ATD may predict a recurrence of depression within 1 year (Moreno et al., 2000; Neumeister, Habeler, Praschak-Rieder, Willeit, \& Kasper, 1999). These findings suggest that response to ATD is a biological vulnerability marker of depression.

From a cognitive perspective, dysfunctional schemas are a core vulnerability marker of depression (Beck, 1967). These schemas are assessed with a self-report scale, the Dysfunctional Attitude Scale (DAS; Weissman, 1979). However, DAS scores normalize when depression is in remission, even when cognitions have not been targeted in treatment (Simons, Garfield, \& Murphy, 1984). Other measures of dysfunctional schemas also covary with clinical status (Lau, Segal, \& Williams, 2004), casting doubt on their hypothesized etiological role in depression. However, it has been shown that dysfunctional schemas do not disappear during remission but become inactive and may be reactivated by relatively mild (nonpathological) increases of sad mood (Miranda \& Persons, 1988; Segal, Williams, Teasdale, \& Gemar, 1996: Sheppard \& Teasdale, 2004; Teasdale, 1988). This may trigger a feedback loop that ends in a recurrence of depression (Lau et al., 2004; Teasdale, 1988).

The extent to which dysfunctional schemas are activated when mood decreases has been labeled cognitive reactivity (CR). CR can be assessed in the laboratory by measuring dysfunctional attitudes before and after a sad mood induction (Miranda, Gross, Persons, \& Hahn, 1998). Euthymic, previously depressed individuals have higher DAS change scores following a sad mood induction than never-depressed individuals, despite similar changes in mood
(Miranda et al., 1998; Segal et al., 1999; Van der Does, 2002a). CR has also been demonstrated with tests of automatic rather than effortful processes. For instance, using an implicit association test, Gemar, Segal, Sagrati, and Kennedy (2001) found an increased negative evaluative bias after a psychological mood induction in individuals with a history of depression as compared with controls. The bias after mood induction was comparable to that observed in individuals with a current depression. High CR also predicted earlier relapses within 1 to 4 years posttreatment (Segal et al., 1999; Segal, Kennedy, Gemar, Sagrati, \& Hood, 2003).

It has been suggested that CR can be assessed by means of self-report questionnaires, the Depressed States Checklist (Teasdale \& Cox, 2001), and the Leiden Index of Depression Sensitivity (LEIDS; Van der Does, 2002a). The LEIDS uses a similar approach to another measure of vulnerability to psychopathology, the Anxiety Sensitivity Index (Peterson \& Reiss, 1992). Whereas the DAS consists of "absolute" statements (e.g., "You can only be happy if you're good-looking, rich, and smart"), the LEIDS asks conditional questions - participants are asked to indicate how their thinking changes when they feel down (e.g., "When in a sad mood, I become more bothered by perfectionism"). In four studies, LEIDS scores distinguished euthymic individuals with and without a history of depression (Merens et al., 2005; Van der Does, 2002a, 2005; Williams, Van der Does, Barnhofer, Crane, \& Segal, 2006). In the first two of these studies the DAS was also administered and did not distinguish between groups. The validity of the LEIDS as a measure of CR is also supported by high correlations with DAS change scores before and after mood inductions (Van der Does, $2002 \mathrm{~b}$ ) and by a correlation of .58 with the Depressed States Checklist (Merens et al., 2005). Finally, the hopelessness/ suicidality subscale of the LEIDS $^{1}$ predicted change in positive future fluency scores, a behavioral measure of hopelessness (Williams et al., 2006).

The aim of the present study was to investigate whether individual differences in cognitive reactivity to sad mood, as indexed by the LEIDS, are related to differences in sensitivity to acute reduction of serotonin concentrations, as indexed by the depressive response to high-dose ATD. Although no prior study has investigated the relationship between cognitive and biological vulnerability markers in a remitted depressed sample, we expected a positive relationship between high CR scores and a larger depressive response to ATD, based on the finding that the $5 \mathrm{HT}_{2}$ agonist fenfluramine improved dysfunctional attitudes in healthy volunteers (Meyer et al., 2003). To investigate the specificity of this relationship, we also investigated the relation between ATD response and two more general markers of vulnerability to psychopathology: neuroticism and behavioral inhibition. These dimensions correlate moderately highly with CR (Van der Does, 2002a). Stewart, Deary, and Ebmeier (2002) found no relationship between response to ATD and neuroticism. However, this study concerned healthy individuals who had no history of depression, and ATD has no significant effect in these samples (Van der Does, 2001). We hypothesized that CR would correlate more strongly with response to ATD than neuroticism or behavioral inhibition, because the latter two are risk factors for negative affective states in

\footnotetext{
${ }^{1}$ The LEIDS can be downloaded at www.dousa.nl/publications
} 
Table 1

Clinical and Demographic Characteristics of the Sample $(N=39)$

\begin{tabular}{|c|c|c|c|c|c|}
\hline \multirow[b]{2}{*}{ Variable } & \multicolumn{5}{|c|}{ Outcome measure } \\
\hline & $n$ & $M$ & $S D$ & $S E$ & Range \\
\hline Men/women & $19 / 20$ & & & & \\
\hline Mean age in years & & 46.05 & 9.88 & & $25-61$ \\
\hline Type of medication: SSRI/SSNRI (2 SSRI treatment free for 1 month) & $27 / 12$ & & & & \\
\hline Mean no. of past episodes & & 4.38 & 5.21 & & $1-21$ \\
\hline Single episode/recurrent episodes & $12 / 27$ & & & & \\
\hline \multicolumn{6}{|l|}{ Mean duration of last episode (in months) } \\
\hline Single episode & & 27.75 & 27.35 & & 4-108 \\
\hline Multiple episodes & & 8.56 & 8.95 & & $1-36$ \\
\hline Mean duration of remission (in months) & & 14.69 & 23.91 & & $1-84$ \\
\hline History of suicidal ideation & 17 & & & & \\
\hline No history of suicidal ideation & 22 & & & & \\
\hline Baseline MADRS & & 6.28 & & 0.68 & $0-15$ \\
\hline Baseline HRSD & & 5.72 & & 0.55 & $0-13$ \\
\hline
\end{tabular}

Note. $\quad$ SSRI $=$ selective serotonin reuptake inhibitor; SSNRI $=$ selective serotonin noradrenalin reuptake inhibitor; MADRS $=$ Montgomery-Asberg Depression Rating Scale; HRSD = Hamilton Depression Rating Scale. History of suicidal ideation is defined as serious suicidal thoughts or attempt during past depression(s).

general (Carver \& White, 1994; Stewart et al., 2002), and thus are nonspecific.

\section{Method}

\section{Participants}

Forty-five patients in remission from a depressive episode entered the study. All of the participants were outpatients of a mood disorder clinic. Inclusion criteria were age between 18 and 65 , ongoing treatment with an SSRI or selective serotonin-noradrenalin reuptake inhibitor (SSNRI) for at least 4 weeks, ${ }^{2}$ meeting criteria from the Diagnostic and Statistical Manual of Mental Disorders, 4th edition (DSM-IV; American Psychiatric Association, 1994) for past major depressive disorder, a Hamilton Depression Rating Scale (HRSD, 17-item version; Hamilton, 1960) score lower than 15 (criteria for partial remission derived from Frank et al., 1991), and a Montgomery-Asberg Depression Rating Scale (MADRS; Montgomery \& Asberg, 1979) score lower or equal to $17 .{ }^{3}$ Exclusion criteria were substance abuse within the last 3 months, psychosis (lifetime), major physical illness, lactation, and pregnancy. All of the patients took part in one of two consecutive ATD experiments on the effects of high-dose and low-dose ATD on neuropsychological functioning (Booij et al., 2006; Booij, Van der Does, Haffmans, Riedel, et al., 2005). The two ATD experiments differed in the composition of a neuropsychological test battery but were identical on all other aspects, including design, procedure, experimenter, research room, symptom assessments, and duration.

Two patients did not complete the self-report questionnaires at intake because of a procedural error. Two patients who fulfilled inclusion and exclusion criteria at intake had elevated MADRS scores on the morning of the high-dose depletion session. Both scores were above the inclusion criterion (24 and 19), and these patients had to be excluded. Two patients did not complete the measurements of the first session because of side effects (one patient in the high-dose condition, the other patient in the control, low-dose condition) and did not take part in the second session. One patient completed all measurements during the high-dose ATD session but did not conduct the control session because of medical reasons unrelated to the experiment. This patient was included in the analyses. The clinical and demographic characteristics of the final sample are presented in Table 1 . All of the patients were paid $€ 115$ (approximately $\$ 147$ ) for participation.

\section{Acute Tryptophan Depletion}

On each ATD session, patients received in randomized order either a 102.5-g (high-dose) mixture or a 25.7-g (low-dose) control mixture of large neutral amino acids (LNAAs) in a natural composition but without Trp. Patients kept a 24-hr low-Trp diet (160 mg/day) prior to both sessions. The mixtures stimulate protein synthesis, which requires Trp. Furthermore, Trp competes with the other AAs for the same transport mechanism into the brain. The composition of the 102.5-g mixture was identical to the mixture used by Delgado et al. (1999). The 102.5-g mixture in combination with the low-Trp diet (high-dose ATD) has been shown to reduce Trp concentrations by approximately $90 \%$ and has a reliable depressive effect in a subgroup of remitted depressed patients (Van der Does, 2001). The 25.7-g control procedure (low-dose ATD) uses the same diet and the same AA mixture but one quarter the amount (Krahn et al., 1996). Low-dose ATD has been shown to reduce Trp concentrations by approximately $40 \%-50 \%$. In the present study, low-dose ATD was used as a placebo procedure, based on the findings that it has no effect on symptoms (Booij, Van der Does, Haffmans, Spinhoven, \& McNally, 2005; Spillmann et al., 2001). AAs were mixed with cold water $\left(4{ }^{\circ} \mathrm{C}\right)$ to a final volume of $300 \mathrm{ml}$. Liquid chocolate syrup was added, and we served the mixtures chilled to improve the unpleasant taste of some of the AAs. During the ATD sessions, water, (de)caffeinated coffee, (herbal) tea, orange juice, and protein-poor $(<0.05 \mathrm{~g})$ cookies were allowed in standard amounts. Patients had a low-Trp lunch $3 \mathrm{hr}$ after drinking the mixture. Although ATD is a chal-

${ }^{2}$ As the response to ATD is larger in SSRI-treated patients than in patients treated with noradrenergic antidepressants (Delgado et al., 1990, Delgado et al., 1999), we only included patients treated with an SSRI to prevent a confound of medication use with the investigated variables of interest.

${ }^{3}$ As the MADRS was used to assess depressive response to ATD, the HRSD was used as an additional screening instrument to prevent bias or an inflation of the relationship for a measure correlated with itself and because of its well-defined cutoff score to define partial remission (Frank et al., 1991). In a sample of 77 outpatients with depression, Mittmann et al. (1997) derived the following formula: MADRS $=1.23 \times$ HRSD (17-item version). Thus, an HRSD score of 14 is equivalent to a MADRS score of 16.92 . 
lenge procedure and may elicit side effects, research suggests that the procedure can be explained well to participants and that it is not seen as a negative experience afterward (Booij, Van der Does, Haffmans, Spinhoven, \& McNally, 2005).

\section{Measures}

Diagnosis, baseline characteristics. A trained clinical psychologist recorded current and past psychiatric diagnoses as well as demographic and clinical background variables using the Structured Clinical Interview for DSM-IV (SCID-I; First, Spitzer, Gibbon, \& Williams, 1995). All information was verified by checking medical records. Residual symptoms experienced during the past 7 days were assessed with both the MADRS (baseline MADRS) and the 17-item version of the HRSD (baseline HRSD; see Footnote 3).

Cognitive reactivity. The LEIDS (Van der Does, 2002a) was used to assess CR. Participants indicate on 5-point scales (0-4) to what extent their cognitions change when they experience a low mood. It is explained in the instructions that low mood does not mean a seriously depressed mood or true depression, and that the task is "to indicate the extent to which the statements apply to you when you feel somewhat sad." The scale has 26 items that cover changes in rumination, hopelessness, aggressive thoughts, risk taking, and perfectionism (e.g., "When I feel sad, I more often think that I can make no one happy"; "When in a sad mood, I more often think about how my life could have been different"; "When I feel down, I more often feel hopeless about everything"; "When I feel somewhat depressed, I think I can permit myself fewer mistakes"). As noted earlier, several studies support the validity of the scale as a measure of CR (Merens et al., 2005; Van der Does, 2002a, 2002b, 2005; Williams et al., 2006). The mean score of the LEIDS was $24.4(S D=12.4)$ in a healthy population and $36.4(S D=15)$ in a previously depressed sample (Van der Does, 2005).

Personality. Neuroticism was measured with the short version of the Eysenck Personality Questionnaire-Revised (EPQ-RSS; Eysenck \& Eysenck, 1991), and behavioral inhibition was measured with the Behavioral Inhibition Scale (BIS/BAS; Carver \& White, 1994). The EPQ-RSS also measures extraversion, psychoticism, and social desirability. The BIS/BAS also contains the Behavioral Activation Scale (BAS), with subscales Drive, Fun Seeking, and Reward Responsiveness.

Symptoms. Residual depressive symptoms before the ATD experiment were measured with the HRSD (Hamilton, 1960). Symptoms during the ATD sessions were assessed with the MADRS (Montgomery \& Asberg, 1979). As in previous ATD studies (see Booij et al., 2003, for a review), the clinical interview was used as a state measure, and the sleep item was not assessed. The MADRS was chosen as outcome variable for response to ATD in favor of the HRSD as it has been shown to be more sensitive to change in antidepressant treatment trials (Montgomery \& Asberg, 1979). It is also more focused on the psychological symptoms of depression, as defined by $D S M-I V$ criteria, than the HRSD (Galinowski \& Lehert, 1995).

\section{Procedure}

Prior to ATD sessions. After providing written informed consent, participants were invited to a screening interview that included the SCID-I, HRSD, MADRS, LEIDS, EPQ-RSS, BIS/BAS, and an interview with a dietician. Patients also completed a neuropsychological test battery. The time between the intake and the first ATD session was approximately 1 week.

ATD sessions. During Day 1 of each session, patients consumed prepacked low-Trp meals at home. Patients came to the laboratory at 8 a.m. or 9 a.m. of Day 2 ( $-1 \mathrm{hr}$ ), after an overnight fast. Symptom ratings were obtained, followed by a blood sample. Next, the ATD drink was consumed $(0 \mathrm{hr})$. For the next $4.5 \mathrm{hr}$, patients remained in a private research room. Neutral videos and magazines were available. At $+5.25 \mathrm{hr}$ patients completed a neuropsychological test battery (not described here). A blood sample was taken at $+6 \mathrm{hr}$. Symptoms were assessed at $+6.5 \mathrm{hr}$. Before participants went home at $+7.25 \mathrm{hr}$, they received a sandwich or a Trp-enriched snack and were instructed to resume their regular meals. Symptom ratings and a blood sample were taken the next morning $(t+24$ $\mathrm{hr}$ ). This procedure was repeated at least 1 week later; those who had received high-dose ATD received the control mixture and vice versa. The study was conducted in a counterbalanced double-blind randomized crossover design. An independent, nationally certified medical ethics committee approved the study, and all patients provided written informed consent after the study had been fully explained.

\section{Statistical Analyses}

Univariate and multivariate general linear models and correlations were used to explore relationships between CR and clinical and demographic variables. We conducted hierarchical multiple regression analyses to predict response to ATD from CR scores. The dependent variable for the regression analyses was the depressive response during high-dose ATD ( $\triangle$ MADRS, $t_{+6.5}-t_{-1}$ ). As gender, recurrent depression, and suicidal tendencies during previous episodes have been shown to be independent predictors of response to ATD (Booij et al., 2002), these variables were reevaluated and forced into the regression equation in case of replicated significance. Next, to investigate the unique contribution of cognitive reactivity and neuroticism and keeping the ratio of sample size and number of predictors under control, we included neuroticism, behavioral inhibition, and cognitive reactivity in the next step of the analysis. We chose to preselect variables based on prior research in favor of selecting those variables in the present data set that correlated highly with ATD response, because this will minimize the chances of a sample-specific regression equation (Stevens, 1996). To further correct for inflated probability of a Type I error and capitalizing on chance, the semipartial correlation of a predictor with the dependent variable in this analysis had to have a $p$ value of .016 or less $(.05 /$ number of predictors entered) to be entered into the regression equation, and its contribution was removed if the $p$ value exceeded .033 (.10/number of predictors entered stepwise). To investigate the influence of the low-dose ATD, we reran all analyses using mood change in that condition as the dependent variable. Finally, to evaluate whether the predictive ability of CR is stronger in the high-dose than the low-dose condition, we carried out a repeated measures regression following the procedure described in Cohen and Cohen (1983). Dose (high dose vs. low dose) and its interaction with $\mathrm{CR}$ were included as predictor variables, with mood change (either during high dose or low dose) as the dependent variable. Additional analyses are described below. Regression models were considered significant if the $p$ value was .05 or less. We evaluated stability and generalizability of the regression model with the best fit by using multicollinearity diagnostic tests and a leave-one-out ("jackknife") procedure. Post hoc power calculations were also done (Cohen, Cohen, West, \& Aiken, 2003). Statistical analyses were conducted by means of SPSS 11.5 on a Windows computer.

\section{Results}

\section{Relation Between Clinical and Demographic Characteristics and $C R$}

Mean LEIDS scores were 36.8 (SEM $=1.9$; Cronbach's $\alpha=.78$ in the present sample). For neuroticism and behavioral inhibition, the means were 6.4 (SEM $=0.6$; Cronbach's $\alpha=.84)$ and 21.2 ( $S E M=0.6$; Cronbach's $\alpha=.78$ ), respectively. Univariate analysis of variance showed that women tended to have higher LEIDS scores than men $(M=40.2, S E M=1.7$ vs. $M=33.2, S E M=$ $3.3), F(1,37)=3.8, p=.06$. LEIDS scores correlated with neuroticism $(r=.40, p=.01)$ and BIS $(r=.44, p=.005)$ and 
moderately with MADRS baseline $(r=.29, p=.09)$. After partialing out the effect of gender, LEIDS correlated significantly with BIS ( $r=.36, p=.03)$ and moderately with neuroticism $(r=$ $.31, p=.06)$ but not with MADRS baseline $(r=.19, p=.25)$. No other clinical or demographic correlates with LEIDS scores were found before or after correcting for a gender difference $(p \geq .11)$.

\section{Mood, Biochemical Effects of ATD}

High-dose ATD reduced total Trp and total Trp/LNAA by $86.0 \%(S E M=0.76)$ and $93.2 \%($ SEM $=0.6)$, respectively. Reductions in the control condition were $48.5 \%(S E M=2.5)$ for total $\operatorname{Trp}$ and $45.6 \%(S E M=2.9)$ for total $\operatorname{Trp} /$ LNAA. The differences between the conditions were significant, $F(1,35)=$ 245.0, $p<.001$ for Trp and, $F(1,35)=277.0, p<.001$, for ratio total Trp/LNAA. Thus, the intervention had the intended biochemical effects. Symptoms on the MADRS scale increased significantly during high-dose depletion session from $4.8(S E M=0.6)$ at $t_{-1}$ to $9.1(S E M=1.2)$ at $t_{+6.5}$. MADRS scores in the low-dose condition changed nonsignificantly from $4.4(S E M=0.7)$ at $t_{-1}$ to $4.7(S E M=0.7)$ at $t_{+6.5}$, and the Intervention $\times$ Time interaction was significant, $F(1,37)=14.8, p<.001$. There were no order effects, as shown by a nonsignificant Intervention $\times$ Time $\times$ Order interaction, $F(1,37)=0.00, p=1.00$.

\section{Predictors of Depressive Response to ATD}

Preselection of variables: Clinical and demographic predictors of response. On the basis of the literature (Booij et al., 2002), we evaluated the influence of recurrent depression (1 episode vs. $>1$ episode), gender, and history of suicidal ideation on ATD response to preselect variables other than $\mathrm{CR}$, neuroticisms, and inhibition to include in the analysis. Regression analysis showed that response was larger in women than in men $(M=5.9, S E M=1.1$ vs. $M=2.8, S E M=1.0), F(1,37)=4.5, p=.04$. None of the clinical and demographic factors mentioned in Table 1 were related to ATD response after partialing out the contribution of gender ( $p \geq$ .11). The difference in depressive response could not be explained by differences in reduction of Trp levels, $F(1,38)=1.39, p=.71$, or ratio Trp/LNAAs, $F(1,38)=0.34, p=.56$. Therefore, only gender was included in the analyses below.

Cognitive reactivity, neuroticism, behavioral inhibition, and ATD response (Table 2, Model 1). The signs of the regression coefficients $(B)$ indicate that being female (Model 1, Step 1) predicts a larger depressive response to ATD. The unique contribution of gender was reduced to a nonsignificant level when CR entered the analysis (Model 1, Step 2). The stepwise analysis did not allow neuroticism or behavioral inhibition to enter the model, as both predictors were not significant $(p=.80$ and $p=.81$, respectively). To investigate whether $\mathrm{CR}$ had significant unique effects above and beyond those of neuroticism and behavioral inhibition, we forced the latter mentioned variables into the equation, followed by an evaluation of the additional effects of CR, if any. A model with neuroticism and BIS but without CR was not significant $\left(R^{2}=.06\right), F(2,36)=1.22, p=.31$. Adding $\mathrm{CR}$ increased multiple $R$ to $.46\left(R^{2}=.21\right), F(1,35)=6.37, p=.016$, and the contribution of CR was significant $(p=.016)$. In both models with and without CR, the contribution of neuroticism and BIS were not significant $(p>.86)$.
Table 2

Summary of the Hierarchical Regression Analyses for Variables Predicting ATD Response $(N=39)$

\begin{tabular}{|c|c|c|c|c|}
\hline Variable & $B$ & $S E B$ & $\beta$ & $p(\beta)$ \\
\hline \multicolumn{5}{|c|}{ Model 1} \\
\hline \multicolumn{5}{|l|}{ Step 1} \\
\hline Gender & 3.11 & 1.47 & .33 & .04 \\
\hline \multicolumn{5}{|l|}{ Step 2} \\
\hline Gender & 1.98 & 1.44 & .21 & .18 \\
\hline LEIDS & 0.16 & 0.06 & .39 & .01 \\
\hline \multicolumn{5}{|c|}{ Model 2} \\
\hline \multicolumn{5}{|l|}{ Step 1} \\
\hline Baseline MADRS & 0.44 & 0.17 & .39 & .01 \\
\hline \multicolumn{5}{|l|}{ Step 2} \\
\hline Baseline MADRS & 0.32 & 0.17 & .29 & .06 \\
\hline LEIDS & 0.15 & 0.06 & .37 & .016 \\
\hline
\end{tabular}

Note. Model 1: $R^{2}=.11$, adjusted $R^{2}=.08$ for Step $1 ; \Delta R^{2}=.14$, adjusted $R^{2}=.20$ for Step 2, $p<.01$ for Step 2. Model 2: $R^{2}=.15$, adjusted $R^{2}=.13$ for Step $1 ; \Delta R^{2}=.13$, adjusted $R^{2}=.24, p<.01$ for Step 2. ATD $=$ acute tryptophan depletion; MADRS = MontgomeryAsberg Depression Rating Scale; LEIDS = Leiden Index of Depression Sensitivity.

Thus, CR predicted depressive response to ATD above and beyond other investigated demographic and clinical variables. Zero-order correlations with ATD response were .46 ( $p=.004)$ for CR, .22 ( $p=$ .19) for neuroticism, and .24 ( $p=.14$ ) for behavioral inhibition.

Cognitive reactivity, residual symptoms, and ATD response (Table 2, Model 2). As residual symptoms (assessed during the intake session and indicated by baseline MADRS) and CR correlated moderately (see above), we investigated whether the effect of $\mathrm{CR}$ remained significant after residual symptoms were entered into the model. Baseline MADRS score was entered first (Model 2, Step 1), followed by CR (Model 2, Step 2). In the two-predictor model, only the contribution of CR was significant. A combined model, entering gender and residual symptoms first, followed by $\mathrm{CR}$, also showed that $\mathrm{CR}$ was the only significant predictor (Table 3). Similar results were obtained when baseline HRSD instead of baseline MADRS was used in the analysis. Finally, we wanted to evaluate whether the effect of CR was still significant when all the other variables that correlated with ATD were partialed out. A hierarchical regression analysis in which all other variables that correlated with ATD response were entered first (gender, residual symptoms, suicidality), followed by $\mathrm{CR}$, showed that CR was the only significant predictor $(p=.05) .^{4}$

\footnotetext{
${ }^{4}$ As the two-predictor model - cognitive reactivity, corrected for residual symptoms - was the most parsimonious model with the best fit, generalizability of this model was further investigated. The multicollinearities among the predictors' residual symptoms and CR were low (variance inflation factor $=1.09$; tolerance level $=0.92$; range condition index $=$ 1.00-7.75). Influence diagnostics were further investigated according to the procedure described in Stevens (1996): for Cook's $D$, range $=0.00$ 0.13; DFBETA, range $=-0.019-0.024$ (LEIDS) and $-0.056-0.05$ (residual symptoms); Mahalonobis distances, range $=0.03-8.90$ (critical value $=11.44 ;$ Stevens, 1996, p. 115); ZRESID (standardized residual),
} 
Table 3

Summary of the Hierarchical Regression Analyses for Variables Predicting ATD Response $(N=39)$

\begin{tabular}{lcccc}
\hline \multicolumn{1}{c}{ Variable } & $B$ & $S E B$ & $\beta$ & $p(\beta)$ \\
\hline Model 3 & & & & \\
$\quad$ Step 1 & & & & \\
$\quad$ Gender & 0.99 & 0.77 & .21 & .21 \\
$\quad$ Baseline MADRS & 0.35 & 0.18 & .31 & .06 \\
Step 2 & & & & .13 \\
$\quad$ Gender & 0.62 & 0.75 & .13 & .13 \\
$\quad$ Baseline MADRS & 0.28 & 0.18 & .24 & .03 \\
$\quad$ LEIDS & 0.14 & 0.06 & .34 & \\
\hline
\end{tabular}

Note. $\quad R^{2}=.19$, adjusted $R^{2}=.15$ for Step $1 ; \Delta R^{2}=.10$, adjusted $R^{2}=$ .23 for Step 2, $p<.01$ for Step 2. ATD = acute tryptophan depletion; MADRS $=$ Montgomery-Asberg Depression Rating Scale; LEIDS = Leiden Index of Depression Sensitivity.

To explore the relationship between ATD response and other personality characteristics, we calculated post hoc correlations between ATD response and the other subscales of the EPQ, including extraversion, psychoticism, and social desirability; between ATD response and the sum score of the BAS; and between ATD response and the scores of the individual subscales of the BAS (reward responsiveness, fun seeking, and drive). None of the correlations, however, were significant $(r<|.22|, p>.19)$.

\section{Effects in the Control Condition, Side Effects}

The correlation between change in symptoms during high-dose ATD and CR changed from $.46(p=.004)$ to $.47(p=.004)$ when the change in symptoms during the control condition was partialed out. An additional post hoc analysis of the low-dose condition in the present study showed that there were no correlations between low-dose ATD response and CR $(r=-.16, p=.32)$. To investigate potential relationships further, we reran regression analysis as described in the section about mood and biochemical effects, except that the change in symptoms following high-dose condition

range $=-1.90-3.03$. Five percent $(n=2)$ of the participants had a ZRESID $>|2|$, supporting the appropriateness of a linear model. One participant had relatively high leverage value $(0.23$; critical value $=0.15$; Stevens, 1996). Other influence diagnostics were normal for this participant (Cook's $D=0.03$; Mahalonobis distance $=8.90$; ZRESID $=0.46$ ).

Generalizability of the model was further evaluated by means of a leave-one-out procedure, using $N-1$ participants. The mean standardized regression coefficients $(\beta)$ for the $N$ regression analysis were 0.29 for residual symptoms (range $=0.24-0.37$ ) and 0.37 for $\mathrm{CR}$ (range $=0.32$ $0.42)$. The mean multiple correlation coefficients $(R)$ varied from 0.49 to $0.59(M=0.53)$. Hence, the differences between the values obtained with $N-1$ participants and the model described in Table 2 were quite small, indicating that the model has good cross-validity power. In all regression analyses, CR significantly predicted ATD response $(p<.05)$ except for one regression model in which $\mathrm{CR}$ had a $p$ value of .05 . $P$ values for residual symptoms ranged from .06 to .10 and were .05 in 4 of the 39 regression analyses.

Effect sizes and power for the two-predictor model (residual symptoms, CR) were calculated by a method described in Cohen et al. (2003). Using the expected population $R^{2}$ of . 24, the estimated effect size $\left(f^{2}\right)$ was .32 . The power was .88 at $\alpha=.05$ and .69 at $\alpha=.01$. was replaced by the change in symptoms in the control condition. None of the regression models predicted symptom change in the control condition to a statistically significant degree $(p \geq .10)$. Finally, to test whether the predictive ability of CR is stronger in the high-dose than in the low-dose condition, we conducted a repeated measure multiple regression following the procedure of Cohen and Cohen (1983). Dosage (low dose vs. high dose) and its interaction with $\mathrm{CR}$ were included as predictors in the regression analysis; symptom change was the dependent variable. The interaction between dose and CR was the only significant predictor $(t=$ $3.19, p=.002 ; B=.19[S E=.06] ; \beta=.77)$. The sign of the beta coefficients indicated that $\mathrm{CR}$ predicted mood response to ATD, but only in the high-dose condition. Similar results were obtained when residual symptoms were also included as a predictor.

\section{Discussion}

The present study shows that patients in remission from depression who score highly on a psychological vulnerability index are more affected by the experimental lowering of serotonin than remitted depressed patients with low $\mathrm{CR}$ scores. Evidence to support the predictive power of CR was derived from several regression models and stability coefficients. Discriminant validity was further supported by the findings that neuroticism and behavioral inhibition were unrelated to ATD response, and neither were other personality characteristics as measured by the EPQ and BIS/BAS scales. Residual symptoms or other clinical factors did not explain the results. As in previous studies, ATD response was higher in women than in men (Booij et al., 2002; Booij, Van der Does, Haffmans, Spinhoven, \& McNally, 2005; Ellenbogen, Young, Dean, Palmour, \& Benkelfat, 1996); however, the gender difference in the present study was no longer significant when $\mathrm{CR}$ entered the equation. No previous ATD studies have assessed CR. The present study suggests that relatively large cognitive changes in response to small (nonpathological) changes in mood (i.e., CR) are an independent predictor of symptomatic changes in response to at least one biological challenge.

Sheppard and Teasdale $(2000,2004)$ suggested that there are two sources of dysfunctional thoughts in depression: (a) increased access to dysfunctional schemas and (b) decreased monitoring of the thoughts and feelings that are the products of these schemas (reduced "metacognitive monitoring"). Their work suggests that patients with depression have a deficit in metacognitive monitoring as well as increased schema accessibility compared with controls (Sheppard \& Teasdale, 2000). Remission is accompanied by improved metacognitive monitoring (e.g., better ability to control negative thoughts); however, accessibility of schemas is still increased (Sheppard \& Teasdale, 2004). Thus, in the course of remission, controlled processing of dysfunctional thoughts improved, but the increased access to schemas remained during periods of nonpathological low mood, which increases the risk of a new episode (Sheppard \& Teasdale, 2004). Improved scores on the DAS may reflect improved metacognitive monitoring rather than reduced access to dysfunctional schemas. The LEIDS, however, consists of state-specific questions concerning the thoughts during a period of low mood. Thus, the LEIDS probably measures access to dysfunctional schemas during low mood rather than metacognitive monitoring, and only the actual access may represent a trait marker for enhanced susceptibility to depression, rather 
than a state factor depending on mood or clinical status. Indeed, LEIDS scores in the present study were similar to those reported in previous studies of fully recovered unmedicated depressed patients (Van der Does, 2005).

A possible mechanism underlying the association between $\mathrm{CR}$ and response to ATD may be that both markers reflect chronicity of illness and, consequently, vulnerability to relapse. Although the present study found no significant relationship between recurrent depression and response to ATD, recurrent depression was the most powerful predictor of ATD response in a previous study (Booij et al., 2002). Other ATD studies also support this association (Neumeister et al., 2004; Smith et al., 1997). The present sample, however, was relatively chronic. Most patients (70\%) had experienced multiple episodes, and patients with only a single episode tended to have had long episodes $(M=27.7$ months, range $=4-108)$. Hence, we could not make a clear distinction between a chronic and a nonchronic group. CR has been found to predict relapse 1-4 years after treatment discontinuation, irrespective of treatment modality (Segal et al., 1999; Segal et al., 2003). Also, a small change of dysfunctional cognitions during acute treatment predicted a shorter time to relapse during a follow-up period (Beevers, Keitner, Ryan, \& Miller, 2003).

The validity of our conclusion that CR predicts response to ATD is highly dependent on the validity of the LEIDS as a measure of $\mathrm{CR}$. The validity of the scale has been supported by studies showing that LEIDS scores predict CR as measured with mood inductions (Van der Does, 2002a, 2002b; Williams et al., 2006). As mentioned earlier, it is of interest that the LEIDS score of our relatively chronic, mostly medicated, and (partially) remitted depressed outpatient group was quite similar to that of unmedicated fully recovered ex-patients (Van der Does, 2005), whereas their baseline depression scores were different. This suggests that CR, as assessed by the LEIDS, represents a trait marker of susceptibility to depression rather than a state factor depending on mood or clinical status.

Dysfunctional cognitions in response to low mood and depressive response to ATD may be brought about by similar underlying, presumably serotonergic mechanisms. Positron emission tomography (PET) studies examining brain glucose metabolism or cerebral blood flow found decreased activity in the medial orbitofrontal cortex in remitted, SSRI-treated patients who responded to ATD (Bremner et al., 1997; Smith, Morris, Friston, Cowen, \& Dolan, 1999). Comparable changes in regional brain activity were observed after a psychological mood induction in currently depressed and in remitted depressed patients but not in controls without a history of depression (Liotti, Mayberg, McGinnis, Brannan, \& Jerabek, 2002). Upregulated 5- $\mathrm{HT}_{2}$ receptors and increased 5- $\mathrm{HT}_{2}$ binding potential have been associated with higher dysfunctional cognitions in depressed patients (Meyer et al., 2003) and with increased 5-HT transporter binding potential in the prefrontal cortex, anterior cingulate, thalamus, caudate, and putamen, using carbon 11-labeled DASB PET (Meyer et al., 2004). In healthy samples, ATD decreased 5- $\mathrm{HT}_{2}$ receptor binding without changing mood (Yatham et al., 2001), and there is indirect evidence that patients who respond to ATD may fail to downregulate 5- $\mathrm{HT}_{2}$ receptors (Yatham et al., 2001). Abnormal regulation of 5- $\mathrm{HT}_{2}$ receptors may be a common underlying mechanism for $\mathrm{CR}$ and ATD response. This hypothesis could be tested in PET studies combining a 5-HT agonist and ATD in remitted depressed patients.
Because we did not include biological challenges other than ATD, it could be argued that CR simply predicts response to any manipulation that effectively elicits depressive symptoms. Additional research is necessary to see if the relationship between $\mathrm{CR}$ and serotonergic manipulations is specific.

Two types of control conditions are used in the ATD literature. In the procedure most commonly used, $2.3 \mathrm{~g}$ Trp is added to the high-dose mixture. It should be pointed out that neither this procedure nor the low-dose procedure that we used is biochemically inactive but can still be used as control conditions as they do not induce any symptoms (see Van der Does, 2001). Low-dose ATD causes similar amounts of side effects as high-dose ATD (Booij, Van der Does, Haffmans, Spinhoven, \& McNally, 2005; Krahn et al., 1996), and participants were unable to distinguish between the mixtures when given in a crossover design (Krahn et al., 1996). Unfortunately, we measured side effects at the point of maximum depletion rather than shortly after intake of the AA mixture, when side effects are probably highest.

The absence of a healthy control group without a history of depression does not limit the interpretation of our findings, because a depressive response to ATD in never-depressed individuals is quite rare. When effects do occur, these are small and limited to high-risk groups, for example, relatives of depressed patients (Benkelfat et al., 1994; Klaassen et al., 1999), in particular those with the 5-HT transporter gene polymorphism of the s/s subtype (Neumeister et al., 2002). Nevertheless, it would be interesting to investigate the relationship between $\mathrm{CR}$ and 5-HT function in these high-risk groups. Furthermore, because ATD also produces depression-congruent cognitive changes (Booij et al., 2005; Murphy et al., 2002), it would be of interest to investigate whether CR is also related to these ATD-induced cognitive changes. Finally, future studies could investigate whether CR scores and response to ATD predict actual relapse of depression and whether different treatment modalities have a different impact on these vulnerability markers.

In conclusion, the present findings show that cognitive reactivity to sad mood predicts depressive symptom response to a 5-HT challenge in depressed patients in remission. In other words, latent depressive schemas are related to a greater sensitivity to a reduction of 5-HT. These findings present a small step toward unifying cognitive and neurobiological theories of depression.

\section{References}

American Psychiatric Association. (1994). Diagnostic and statistical manual of mental disorders (4th ed.). Washington, DC: Author.

Beck, A. T. (1967). Depression: Clinical, experimental and theoretical aspects. New York: Harper \& Row.

Beevers, C. G., Keitner, G. I., Ryan, C. E., \& Miller, I. W. (2003). Cognitive predictors of symptom return following depression treatment. Journal of Abnormal Psychology, 112, 488-496.

Benkelfat, C., Ellenbogen, M. A., Dean, P., Palmour, R. M., \& Young, S. N. (1994). Mood-lowering effect of tryptophan depletion: Enhanced susceptibility in young men at genetic risk for major affective disorders. Archives of General Psychiatry, 51, 687-697.

Booij, L., Swenne, C. A., Brosschot, J. F., Haffmans, P. M. J., Thayer, J. F., \& Van der Does, A. J. W. (2006). Tryptophan depletion affects heart rate variability and impulsivity in remitted depressed patients with a history of suicidal ideation. Biological Psychiatry, 60, 507-514.

Booij, L., Van der Does, A. J. W., Benkelfat, C., Bremner, J. D., Cowen, 
P. J., Fava, M., et al. (2002). Predictors of mood response to acute tryptophan depletion: A reanalysis. Neuropsychopharmacology, 27, $852-861$

Booij, L., Van der Does, A. J. W., Haffmans, P. J., Riedel, W. J., Fekkes, D., \& Blom, M. J. (2005). The effects of high-dose and low-dose tryptophan depletion on mood and cognitive functions in remitted depressed patients. Journal of Psychopharmacology, 3, 865-872.

Booij, L., Van der Does, A. J. W., Haffmans, P. M., Spinhoven, P., \& McNally, R. J. (2005). Acute tryptophan depletion in remitted depressed patients: Behavioural specificity and ethical considerations. British Journal of Psychiatry, 187, 148-154.

Booij, L., Van der Does, A. J. W., \& Riedel, W. J. (2003). Monoamine depletion in psychiatric and healthy populations: Review. Molecular Psychiatry, 8, 951-973.

Bremner, J. D., Innis, R. B., Salomon, R. M., Staib, L. H., Ng, C. K., Miller, H. L., et al. (1997). Positron emission tomography measurement of cerebral metabolic correlates of tryptophan depletion-induced depressive relapse. Archives of General Psychiatry, 54, 364-374.

Carpenter, L. L., Anderson, G. M., Pelton, G. H., Gudin, J. A., Kirwin, P. D., Price, L. H., et al. (1998). Tryptophan depletion during continuous CSF sampling in healthy human subjects. Neuropsychopharmacology, 19, 26-35.

Carver, C. S., \& White, T. L. (1994). Behavioral inhibition, behavioral activation, and affective responses to impending reward and punishment: The BIS/BAS scales. Journal of Personality and Social Psychology, 67, 319-333.

Cohen, J., \& Cohen, P. (1983). Applied multiple regression/correlation analysis for the behavioral sciences (2nd ed.). Hillsdale, NJ: Erlbaum.

Cohen, J., Cohen, P., West, S. G., \& Aiken, L. S. (2003). Applied multiple regression/correlation analysis for the behavioral sciences (3rd ed.). Mahwah, NJ: Erlbaum.

Delgado, P. L., Charney, D. S., Price, L. H., Aghajanian, G. K., Landis, H., \& Heninger, G. R. (1990). Serotonin function and the mechanism of antidepressant action: Reversal of antidepressant-induced remission by rapid depletion of plasma tryptophan. Archives of General Psychiatry, 47, 411-418.

Delgado, P. L., Miller, H. L., Salomon, R. M., Licinio, J., Krystal, J. H., Moreno, F. A., et al. (1999). Tryptophan-depletion challenge in depressed patients treated with desipramine or fluoxetine. Biological Psychiatry, 46, 212-220.

DeRubeis, R. J., Hollon, S. D., Amsterdam, J. D., Shelton, R. C., Young, P. R., Salomon, R. M., et al. (2005). Cognitive therapy vs. medications in the treatment of moderate to severe depression. Archives of General Psychiatry, 62, 409-416.

Ellenbogen, M. A., Young, S. N., Dean, P., Palmour, R. M., \& Benkelfat, C. (1996). Mood response to acute tryptophan depletion in healthy volunteers: Sex differences and temporal stability. Neuropsychopharmacology, 15, 465-474.

Elliott, R. (1998). The neuropsychological profile in unipolar depression. Trends in Cognitive Sciences, 2, 447-454.

Eysenck, H. J., \& Eysenck, S. B. G. (1991). Manual of the Eysenck Personality Scales. London: Hodder \& Stoughton.

First, M. B., Spitzer, R. L., Gibbon, M., \& Williams, J. B. (1995). Structured Interview for DSM-IV Axis I disorders (SCID-I/P). New York: New York State Psychiatric Institute, Biometrics Research Department.

Frank, E., Prien, R. F., Jarrett, R. B., Keller, M. B., Kupfer, D. J., Lavori, P. W., et al. (1991). Conceptualization and rationale for consensus definitions of terms in major depressive disorder: Remission, recovery, relapse, and recurrence. Archives of General Psychiatry, 48, 851-855.

Galinowski, A., \& Lehert, P. (1995). Structural validity of MADRS during antidepressant treatment. International Clinical Psychopharmacology, 10, 157-161.

Gemar, M. C., Segal, Z. V., Sagrati, Z. V., \& Kennedy, S. J. (2001).
Mood-induced changes on the implicit association test in recovered depressed patients. Journal of Abnormal Psychology, 110, 282-289.

Hamilton, M. (1960). A rating scale for depression. Journal of Neurology, Neurosurgery and Psychiatry, 23, 56-62.

Harmer, C. J., Mackay, C. E., Reid, C. B., Cowen, P. J., \& Goodwin, G. M. (2006). Antidepressant drug treatment modifies the neural processing of nonconscious threat cues. Biological Psychiatry, 59, 816-820.

Harmer, C. J., Rogers, R. D., Tunbridge, E., Cowen, P. J., \& Goodwin, G. M. (2003). Tryptophan depletion decreases the recognition of fear in female volunteers. Psychopharmacology, 167, 411-417.

Harmer, C. J., Shelley, N. C., Cowen, P. J., \& Goodwin, G. M. (2004). Increased positive versus negative affective perception and memory in healthy volunteers following selective serotonin and norepinephrine reuptake inhibition. American Journal of Psychiatry, 161, 1256-1263.

Ising, M., Kunzel, H. E., Binder, E. B., Nickel, T., Modell, S., \& Holsboer, F. (2005). The combined dexamethasone/CRH test as a potential surrogate marker in depression. Progress in Neuropsychopharmacology and Biological Psychiatry, 29, 1085-1093.

Judd, L. L., Paulus, M. P., \& Zeller, P. (1999). The role of residual subthreshold depressive symptoms in early episode relapse in unipolar major depressive disorder. Archives of General Psychiatry, 56, 764765.

Keller, M. B. (1999). Long-term treatment of recurrent and chronic depression. Journal of Clinical Psychiatry, 62(Suppl. 24), 3-5.

Klaassen, T., Riedel, W. J., Van Someren, A., Deutz, N. E., Honig, A., \& Van Praag, H. M. (1999). Mood effects of 24-hour tryptophan depletion in healthy first-degree relatives of patients with affective disorders. Biological Psychiatry, 46, 489-497.

Krahn, L. E., Lu, P. Y., Klee, G., Delgado, P. L., Lin, S. C., \& Zimmermann, R. C. (1996). Examining serotonin function: A modified technique for rapid tryptophan depletion. Neuropsychopharmacology, 15, $325-328$.

Kuehner, C., \& Weber, I. (1999). Responses to depression in unipolar depressed patients: An investigation of Nolen-Hoeksema's response styles theory. Psychological Medicine, 29, 1323-1333.

Lau, M. A., Segal, Z. V., \& Williams, J. M. G. (2004). Teasdale's differential activation hypothesis: Implications for mechanisms of depressive relapse and suicidal behaviour. Behaviour Research and Therapy, 42, 1001-1017.

Liotti, M., Mayberg, H. S., McGinnis, S., Brannan, S. L., \& Jerabek, P. (2002). Unmasking disease-specific cerebral blood flow abnormalities: Mood challenge in patients with remitted unipolar depression. American Journal of Psychiatry, 159, 1830-1840.

Maes, M., \& Meltzer, H. Y. (1995). The serotonin hypothesis of major depression. In F. E. Bloom \& D. J. Kupfer (Eds.), Psychopharmacology: The fourth generation of progress (pp. 933-944). New York: Raven Press.

Merens, W., Booij, L., Markus, R. C., Zitman, F. G., Onkenhout, W., \& Van der Does, A. J. W. (2005). The effects of a diet enriched with alpha-lactalbumin on mood and cortisol response in unmedicated recovered depressed subjects and controls. British Journal of Nutrition, 94, 415-422.

Meyer, J. H., Houle, S., Sagrati, S., Carella, A., Hussey, D. F., Ginovart, N., et al. (2004). Brain serotonin transporter binding potential measured with carbon 11-labeled DASB positron emission tomography. Archives of General Psychiatry, 61, 1271-1279.

Meyer, J. H., McMain, S., Kennedy, S. H., Korman, L., Brown, G. M., DaSilva, J. N., et al. (2003). Dysfunctional attitudes and 5- $\mathrm{HT}_{2}$ receptors during depression and self-harm. American Journal of Psychiatry, 160, 90-99.

Miranda, J., Gross, J. J., Persons, J. B., \& Hahn, J. (1998). Mood matters: Negative mood induction activates dysfunctional attitudes in women vulnerable to depression. Cognitive Therapy and Research, 22, 363-376. 
Miranda, J., \& Persons, J. B. (1988). Dysfunctional attitudes are moodstate dependent. Journal of Abnormal Psychology, 97, 76-79.

Mittmann, N., Mitter, S., Borden, E. K., Herrmann, N., Narnajo, C. A., \& Shear, N. H. (1997). Montgomery-Asberg severity gradations. American Journal of Psychiatry, 154, 1320-1321.

Montgomery, S. A., \& Asberg, M. (1979). A new depression scale designed to be sensitive to change. British Journal of Psychiatry, 134, 382-389.

Moreno, F. A., Henninger, G. R., McGahuey, C. A., \& Delgado, P. L. (2000). Tryptophan depletion and risk of depression relapse: A prospective study of tryptophan depletion as a potential predictor of depressive episodes. Biological Psychiatry, 48, 327-329.

Morilak, D. A., \& Frazer, A. (2004). Antidepressants and brain monoaminergic systems: A dimensional approach to understanding their behavioural effects in depression and anxiety disorders. International Journal of Neuropsychopharmacology, 7, 193-218.

Mueller, T. I., Leon, A. C., Keller, M. B., Solomon, D. A., Endicott, J., Coryell, W., et al. (1999). Recurrence after recovery from major depressive disorder during 15 years of observational follow-up. American Journal of Psychiatry, 156, 1000-1006.

Murphy, F. C., Smith, K. A., Cowen, P. J., Robbins, T. W., \& Sahakian, B. J. (2002). The effects of tryptophan depletion on cognitive and affective processing in healthy volunteers. Psychopharmacology, 163, $42-53$.

Neumeister, A., Habeler, A., Praschak-Rieder, N., Willeit, M., \& Kasper, S. (1999). Tryptophan depletion: A predictor of future episodes in seasonal affective disorder? International Journal of Clinical Psychopharmacology, 14, 313-315.

Neumeister, A., Konstantinidis, A., Stastny, J., Schwarz, M. J., Vitouch, O., Willeit, M., et al. (2002). Association between serotonin transporter gene promoter polymorphism (5HTTLPR) and behavioral responses to tryptophan depletion in healthy women with and without family history of depression. Archives of General Psychiatry, 59, 613-620.

Neumeister, A., Nugent, A. C., Waldeck, T., Geraci, M., Schwarz, M., \& Bonne, O. (2004). Neural and behavioral responses to tryptophan depletion in unmedicated patients with remitted major depressive disorder and controls. Archives of General Psychiatry, 61, 765-773.

Nishizawa, S., Benkelfat, C., Young, S. N., Leyton, M., Mzengeza, S., de Montigny, C., et al. (1997). Differences between males and females in rates of serotonin synthesis in human brain. Proceedings of the National Academy of Sciences, USA, 94, 5308-5313.

Peterson, R. A., \& Reiss, S. (1992). Anxiety sensitivity index manual (2nd ed.). Worthington, $\mathrm{OH}$ : International Diagnostic Systems.

Riedel, W. J., Klaassen, T., Deutz, N. E., van Someren, A., \& Van Praag, H. M. (1999). Tryptophan depletion in normal volunteers produces selective impairment in memory consolidation. Psychopharmacology, 141, 362-369.

Schmitt, J. A., Jorissen, B. L., Sobczak, S., van Boxtel, M. P., Hogervorst, E., Deutz, N. E., et al. (2000). Tryptophan depletion impairs memory consolidation but improves focussed attention in healthy young volunteers. Journal of Psychopharmacology, 14, 21-29.

Segal, Z. V., Gemar, M., \& Williams, S. (1999). Differential cognitive response to a mood challenge following successful cognitive therapy or pharmacotherapy for unipolar depression. Journal of Abnormal Psychology, 108, 3-10.

Segal, Z. V., Kennedy, S., Gemar, M., Sagrati, S., \& Hood, K. (2003, November). Mood-linked cognitive therapy, depressive relapse and remission following either cognitive therapy or pharmacotherapy. Paper presented at the 37th Annual Convention of the Association for Advancement of Behavior Therapy, Boston.

Segal, Z. V., Williams, J. M., Teasdale, J. D., \& Gemar, M. A. (1996). A cognitive science perspective on kindling and episode sensitization in recurrent affective disorder. Psychological Medicine, 26, 371-380.

Sheppard, L. C., \& Teasdale, J. D. (2000). Dysfunctional thinking in major depressive disorder: A deficit in metacognitive monitoring? Journal of Abnormal Psychology, 109, 768-776.

Sheppard, L. C., \& Teasdale, J. D. (2004). How does dysfunctional thinking decrease during recovery from major depression? Journal of Abnormal Psychology, 113, 64-71.

Simons, A. D., Garfield, S. L., \& Murphy, G. E. (1984). The process of change in cognitive therapy and pharmacotherapy in depression: Changes in mood and cognition. Archives of General Psychiatry, 41, $45-51$.

Smith, K. A., Fairburn, C. G., \& Cowen, P. J. (1997). Relapse of depression after rapid depletion of tryptophan. Lancet, 349, 915-919.

Smith, K. A., Morris, J. S., Friston, K. J., Cowen, P. J., \& Dolan, R. J. (1999). Brain mechanisms associated with depressive relapse and associated cognitive impairment following acute tryptophan depletion. British Journal of Psychiatry, 174, 525-529.

Spillmann, M. K., Van der Does, A. J. W., Rankin, M. A., Vuolo, R. D., Alpert, J. E., Nierenberg, A. A., et al. (2001). Tryptophan depletion in SSRI-recovered depressed outpatients. Psychopharmacology, 155, 123127.

Stevens, J. (1996). Applied multivariate statistics for the social sciences (3rd ed.). Hillsdale, NJ: Erlbaum.

Stewart, M. E., Deary, I. J., \& Ebmeier, K. P. (2002). Neuroticism as a predictor of mood change: The effects of tryptophan depletion. British Journal of Psychiatry, 181, 242-247.

Teasdale, J. D. (1988). Cognitive vulnerability to persistent depression. Cognition \& Emotion, 2, 247-274.

Teasdale, J. D., \& Cox, S. G. (2001). Dysphoria: Self-devaluative and affective components in recovered depressed patients and never depressed controls. Psychological Medicine, 31, 1311-1316.

Van der Does, A. J. W. (2001). The effects of tryptophan depletion on mood and psychiatric symptoms. Journal of Affective Disorders, 64, $107-119$.

Van der Does, A. J. W. (2002a). Cognitive reactivity to sad mood: Structure and validity of a new measure. Behaviour Research and Therapy, 40, 105-120.

Van der Does, A. J. W. (2002b). Different types of experimentally induced sad mood? Behavior Therapy, 33, 551-561.

Van der Does, A. J. W. (2005). Thought suppression and cognitive vulnerability to depression. British Journal of Clinical Psychology, 44, $1-14$.

Weissman, A. N. (1979). The Dysfunctional Attitude Scale (Doctoral dissertation, University of Pennsylvania). Dissertation Abstracts International, 40, 1389B-1390B.

Williams, J. M. G., Van der Does, A. J. W., Barnhofer, T., Crane, C., \& Segal, Z. V. (2006). Cognitive reactivity and suicidal ideation: Testing a differential activation theory of suicidality. Manuscript submitted for publication.

Yatham, L. N., Liddle, P. F., Shiah, I. S., Lam, R. W., Adam, M. J., Zis, A. P., et al. (2001). Effects of rapid tryptophan depletion on brain 5-HT receptors: A PET study. British Journal of Psychiatry, 178, 448-453.

Young, S. N., Smith, S. E., Pihl, R. O., \& Ervin, F. R. (1985). Tryptophan depletion causes a rapid lowering of mood in normal males. Psychopharmacology, 87, 173-177.

Received January 10, 2005

Revision received July 6, 2006 Accepted July 9, 2006 